\title{
Improved Outcomes When Antibiotic Prescribing Guidelines Are Followed by Healthcare Providers: A Colombian Example to Encourage Adherence in Hospital Settings - CORRIGENDUM
}

In the article by Feinstein et $\mathrm{al}^{1}$ the middle initial of the first author (Max M. Feinstein) was not included in the final published article. The original article has been updated to include the middle initial.

\section{REFERENCE}

1. Feinstein MM, Escandón-Vargas K, Reyes S, Hernández-Gómez C, Pallares CJ, Villegas MV. Improved Outcomes When Antibiotic

\begin{abstract}
Prescribing Guidelines Are Followed by Healthcare Providers: A Colombian Example to Encourage Adherence in Hospital Settings. Infection Control Hosp Epidemiol 2017;38:756-758.
\end{abstract}

